DeAr Sirs

I agree with Chris Green (Psychiatric Bulletin, August 1992, 16, 511-512) that in practice juries are more influenced by intangibles than by the application of the definition of diminished responsibility in the Homicide Act 1959. When I was examining a number of offenders at the request of both the prosecution or the defence, I became increasingly convinced that the more sensational and horrific the alleged offence the less likely the jury was to accept evidence of diminished responsibility, however overwhelming this appeared to be from a psychiatric point of view. As a result, I came to believe, as others before me, that juries' own responsibilities should be substantially diminished and limited to deciding guilt or innocence on the basis of the evidence presented to them and that, in the event of the former verdict, any consideration of the offender's mental state should be by a panel similar to a Mental Health Review Tribunal hearing appeals by restricted Section 37/41 cases - a view which I submitted in written evidence to the Royal Commission on the Criminal Justice System.

Flat 2,

W. Alan Heaton-Ward

38 Apsley Road

Clifton, Bristol BS8 2SS

\section{Mental health services in Brighton}

DeAR Sirs

We read with interest the views of John Mahoney on resources for developing mental health services (Psychiatric Bulletin, August 1992, 16, 490-492).

While we agree with the significant role which districts and regions need to play in providing bridging finance for services in transition, caution needs to be applied to using unit costs as an indication of available resources.

Although Brighton was indeed in the top 10 of high unit costs in the survey of 57 institutions in 1983, the unit referred to only had 42 beds and therefore this did not mean that Brighton had a large budget for mental health services to reallocate!

In fact, the development of a comprehensive community based mental health service in Brighton since 1983 has been mainly achieved by the transfer back of 100 people from out of district large institutions. The majority of these came from one hospital which was not even in the same region as Brighton and only marginal costs were transferred with each patient. The bridging funding then provided by South East Thames Regional Health Authority did greatly assist with enabling Brighton to achieve its service developments. However, this year we are transferring back a further 40 people to community based residential services in Brighton. We will achieve this without the benefit of any capital funding from either district or region, but through making the maximum use of our good working relationships with the local Social Services and housing associations.

The decision to proceed with this new reprovision programme was only made in September 1991 and at least 20 people will move to their new homes in November 1992.

While agreeing with the relevance and importance of all the issues which John Mahoney identifies, three other key issues are: the use of sensible staff skill mix (using trained but not necessarily professionally qualified staff in residential services); actively supporting the development of a local mixed economy of care; and management and clinical determination and drive which are able to exploit all possible avenues and maintain the momentum of change with quick and responsible decision making.

S. G. HoOD

Brighton General Hospital

M. ROSENBERG

Brighton BN2 3EW

\section{Relatives who refuse to given consent}

DeAr Sirs

I read with interest the letter from Sean Scanlon (Psychiatric Bulletin, August 1992, 16, 513-514) and would like to make the following comments.

(a) Dr Scanlon comments that it should be enough to do all one can, and there is no need to feel helpless. This is naive. When a patient is mentally ill, and treatment is being withheld because of the view of the next of kin, I suspect most reasonable psychiatrists would feel helpless.

(b) The author says that the process of displacement of next of kin is not long and complicated and to support this incorrect claim gives the reasons why it should be!

(c) He uses one example to support his claims. I suggest that his experience is the exception and would like to hear other peoples' experience of this issue.

\section{Halifax General Hospital}

JANE O'DWYER Halifax $\mathrm{HX} 3 \mathrm{OPW}$

\section{Ranking of therapeutic and toxic-side effects of lithium carbonate}

\section{DeAr Sirs}

Dr Colgate is to be congratulated on (Psychiatric Bulletin, August 1992, 16, 473-475) drawing attention to the lack of clarity in prescribers' information for lithium medication. 